\title{
Erythropoietin promotes breast tumorigenesis through tumor-initiating cell self-renewal
}

\author{
Bing Zhou, ${ }^{1}$ Jeffrey S. Damrauer, ${ }^{1}$ Sean T. Bailey, ${ }^{1}$ Tanja Hadzic, ${ }^{1}$ Youngtae Jeong, ${ }^{2}$ Kelly Clark, ${ }^{1}$ \\ Cheng Fan, ${ }^{1}$ Laura Murphy, ${ }^{1}$ Cleo Y. Lee, ${ }^{2}$ Melissa A. Troester, ${ }^{3}$ C. Ryan Miller, ${ }^{4}$ Jian Jin, ${ }^{1,5}$ \\ David Darr, ${ }^{1}$ Charles M. Perou, ${ }^{1}$ Ross L. Levine, ${ }^{6}$ Maximilian Diehn, ${ }^{2}$ and William Y. Kim ${ }^{1}$
}

\begin{abstract}
${ }^{1}$ Lineberger Comprehensive Cancer Center, University of North Carolina at Chapel Hill, Chapel Hill, North Carolina, USA.
2Department of Radiation Oncology, Cancer Institute, and Institute for Stem Cell Biology and Regenerative Medicine, Stanford University School of Medicine, Stanford, California, USA. ${ }^{3}$ Department of Epidemiology and ${ }^{4}$ Department of Pathology and Laboratory Medicine, University of North Carolina at Chapel Hill, Chapel Hill, North Carolina, USA. ${ }^{5}$ Center for Integrative Chemical Biology and Drug Discovery, Division of Chemical Biology and Medicinal Chemistry, UNC Eshelman School of Pharmacy, Chapel Hill, North Carolina, USA. ${ }^{6}$ Human Oncology and Pathogenesis Program, Leukemia Service, Department of Medicine, Memorial Sloan-Kettering Cancer Center, New York, New York, USA.
\end{abstract}

\begin{abstract}
Erythropoietin (EPO) is a hormone that induces red blood cell production. In its recombinant form, EPO is the one of most prescribed drugs to treat anemia, including that arising in cancer patients. In randomized trials, EPO administration to cancer patients has been associated with decreased survival. Here, we investigated the impact of EPO modulation on tumorigenesis. Using genetically engineered mouse models of breast cancer, we found that EPO promoted tumorigenesis by activating JAK/STAT signaling in breast tumor-initiating cells (TICs) and promoted TIC self renewal. We determined that EPO was induced by hypoxia in breast cancer cell lines, but not in human mammary epithelial cells. Additionally, we demonstrated that high levels of endogenous $E P O$ gene expression correlated with shortened relapse-free survival and that pharmacologic JAK2 inhibition was synergistic with chemotherapy for tumor growth inhibition in vivo. These data define an active role for endogenous EPO in breast cancer progression and breast TIC self-renewal and reveal a potential application of EPO pathway inhibition in breast cancer therapy.
\end{abstract}

\section{Introduction}

The glycoprotein hormone erythropoietin (EPO) is principally produced in the tubulointerstitial cells of the kidney in adults and is the chief regulator of erythropoiesis. EPO couples red blood cell production to tissue oxygenation through an oxygensensing system mediated by the HIF family of transcription factors, of which there are 3 family members (HIF1 $\alpha, H I F 2 \alpha$, and $H I F 3 \alpha)(1)$. Genetic evidence suggests that $\mathrm{EPO}$ is regulated at the transcriptional level by HIF2 $\alpha(2-5)$.

EPO activates the transmembrane EPO receptor (EPO-R), located primarily on erythroid progenitor cells $(6-8)$. The EPO-R lacks intrinsic kinase activity and thus relies on its association with the intracellular kinase JAK2 to initiate context-dependent signal transduction cascades such as the PI3K, MEK/ERK, and STAT pathways (6-9).

Hypoproliferative anemia affects over $75 \%$ of all cancer patients and recombinant human $\mathrm{EPO}$ ( $\mathrm{rHuEPO}$ ) is FDA approved for the treatment of chemotherapy-induced anemia (10). Its positive effects on quality of life led to its widespread use in clinical oncology. However, recently, several prospective, randomized trials have shown that administration of erythropoiesis-stimulating agents (ESAs) during treatment results in both a shorter time to tumor progression and overall survival of cancer patients (11-17). Nonetheless, the negative impact of $\mathrm{EPO}$ in cancer patients remains controversial, as some

Authorship note: Bing Zhou and Jeffrey S. Damrauer contributed equally to this work. Conflict of interest: The authors have declared that no conflict of interest exists.

Note regarding evaluation of this manuscript: Manuscripts authored by scientists associated with Duke University, The University of North Carolina at Chapel Hill, Duke-NUS, and the Sanford-Burnham Medical Research Institute are handled not by members of the editorial board but rather by the science editors, who consult with selected external editors and reviewers.

Citation for this article: J Clin Invest. 2014;124(2):553-563. doi:10.1172/JCI69804. other studies have also shown no detrimental effect of EPO if the target hemoglobin $(\mathrm{Hgb})$ is approximately $10 \mathrm{~g} / \mathrm{dl}$ (18-21).

A number of preclinical studies have examined the role of EPO with a wide range of in vitro findings $(6-8,22-27)$. In contrast, in various in vivo xenograft tumor models, exogenous EPO does not significantly promote tumor growth or result in resistance to therapy $(6-8,22,23)$ with the exception of Lewis lung carcinoma xenografts and carcinogen-induced fibrosarcomas (28). Therefore, there is a disconnect between the in vitro results that suggest a protumorigenic effect of EPO and the in vivo results, which do not.

We found that exogenous EPO did not have appreciable effects on cellular proliferation or protect from chemotherapy-induced apoptosis in vitro. In contrast, EPO promoted in vivo tumor progression of 2 autochthonous genetically engineered murine models (GEMMs) of breast cancer as well as cell lines derived from GEMM tumors when injected orthotopically. While the bulk populations of these tumor cell lines were not responsive to EPO in vitro, treatment of breast tumor-initiating cells (TICs) with EPO activated JAK/STAT signaling as well as promoted their self renewal. Finally, we show several lines of evidence that endogenous EPO plays a protumorigenic role in breast tumorigenesis. We show that breast cancer cells as well as tumor-associated endothelial cells can produce EPO and that $E P O$ expression within human breast tumors correlates negatively with progression-free survival. Additionally, JAK2 inhibition cooperates with chemotherapy to decrease tumor growth. These findings suggest an active role for endogenous EPO in tumor progression and argue for a potential role of targeting the EPO pathway in breast cancer therapy.

\section{Results}

EPO does not affect buman breast cancer cell lines in vitro. Based on previously reported data suggesting a protumorigenic role of EPO in 

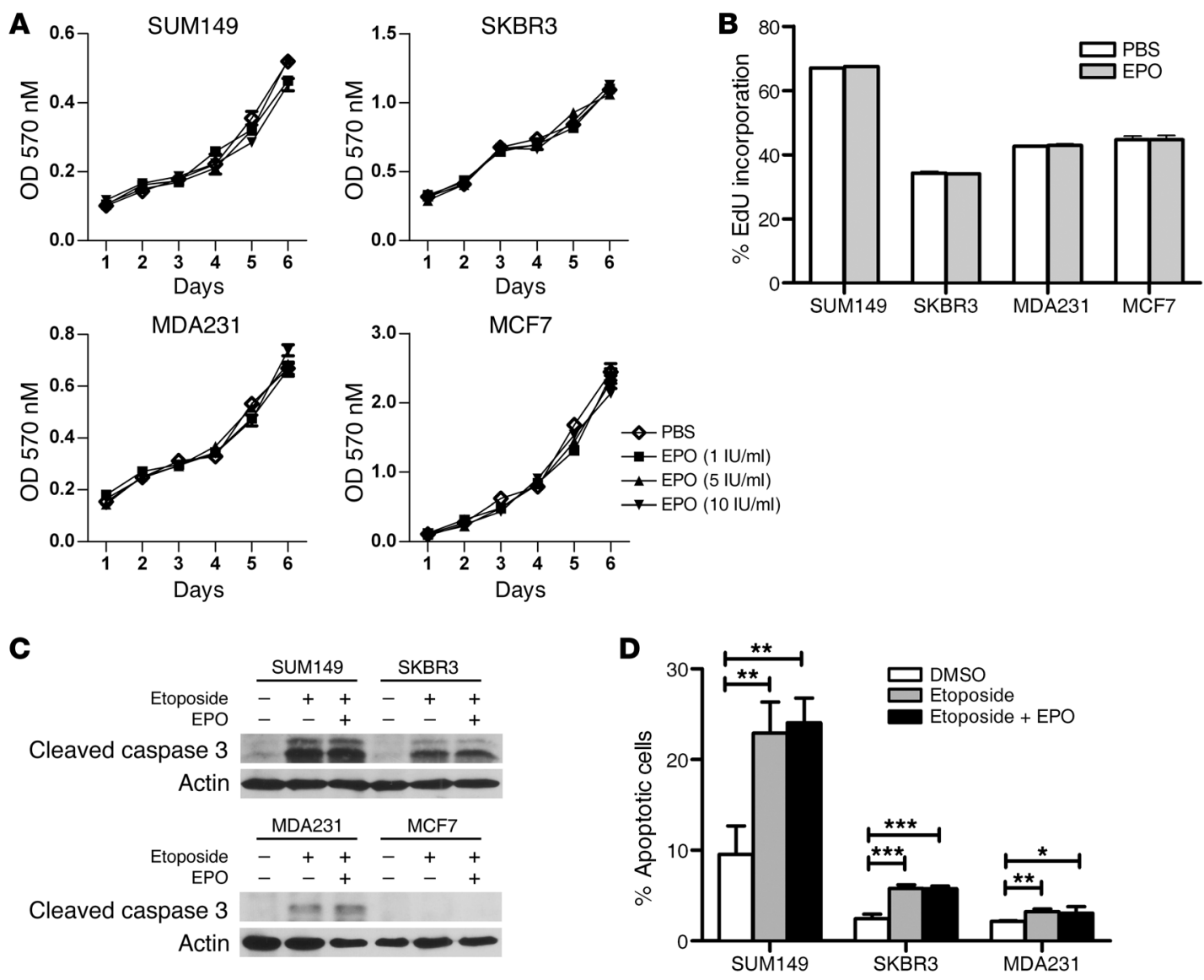

\section{Figure 1}

EPO does not affect human breast cancer cell lines in vitro. (A) Indicated cell lines were cultured in the presence of increasing concentrations of $\operatorname{EPO}(1,5$, and $10 \mathrm{IU} / \mathrm{ml}$, replenished every other day), and proliferation was detected by MTT assay. (B) Cell lines were cultured in the presence of PBS or EPO $(1 \mathrm{IU} / \mathrm{ml})$ for 16 hours and EdU for 1 hour. They were then analyzed for EdU incorporation by flow cytometry. (C) Indicated cell lines were treated with vehicle, etoposide $(50 \mu \mathrm{M})$, or etoposide $(50 \mu \mathrm{M})$ and EPO $(10 \mathrm{IU} / \mathrm{ml})$ for 24 hours. Whole-cell extracts were Western blotted with the indicated antibodies. (D) Indicated cell lines were treated with DMSO, etoposide $(50 \mu \mathrm{M})$, or etoposide $(50 \mu \mathrm{M})$ and EPO (10 IU/ml) for 24 hours, then stained with $\mathrm{PI}$ and antibodies against annexin $\mathrm{V}$. The percentages of cells that were annexin $\mathrm{V}$ positive and $\mathrm{PI}$ negative were quantified by flow cytometry. ${ }^{\star} P \leq 0.05 ;{ }^{* *} P \leq 0.01 ;{ }^{* *} P \leq 0.001$.

breast cancer, we wished to explore the impact of EPO in vitro. In our hands, neither proliferation nor cell-cycle progression were altered by increasing amounts of EPO (Figure 1, A and B). Similarly, EPO did not appear to protect against chemotherapy-induced apoptosis (Figure 1, C and D). Despite several of these cell lines expressing the EPO-R, exogenous EPO did not appear to appreciably increase JAK/STAT signaling (Supplemental Figure 1, A and B; supplemental material available online with this article; doi:10.1172/ JCI69804DS1). Thus, based on these assays, in our hands, EPO does not appear to be relevant for the in vitro growth properties or survival of breast cancers cells grown as monolayer cultures.

EPO decreases the survival of breast GEMMs but has no effect on $G E M M$-derived cell lines in vitro. The majority of in vivo studies have not demonstrated a protumorigenic effect of $\operatorname{EPO}(6,7,22,23$, 29-32). We noted that these studies utilized xenografts or carcinogen-induced tumors and hypothesized that GEMMs would serve as a more relevant context to address this issue, providing tumors arising in a native setting and allowing us to administer EPO for longer intervals. To this end, we administered clinically relevant doses of exogenous EPO that minimally elevated Hgb and Hct levels (Supplemental Figure 2A) to 2 independent breast cancer GEMMs (MMTV-Neu and C3-Tag) $(33,34)$. The percentage of mice living over time was significantly shorter in EPO-treated MMTVNeu mice $(P=0.05$, Figure $2 A)$, with a median survival of 20.6 and 15.7 weeks in the saline- and EPO-treated groups respectively. Similar results were seen in the $C 3$-Tag model $(P=0.04$, Figure $2 \mathrm{~A})$. The decreased percentage of mice living appeared to be a reflection of a shortened tumor-free survival (Supplemental Figure 2, B and C). There were no apparent differences in $\mathrm{H} \& \mathrm{E}$ histology between PBS- and EPO-treated tumors (Figure 2A) or their proliferation and vascularity as assessed by Ki67 and CD31 staining (Supplemental Figure 3, A and B).

We next generated cell lines from C3-Tag tumors and obtained the NT2 line derived from MMTV-Nen tumors (E. Jaffee, Johns Hopkins University, Baltimore, Maryland, USA). We confirmed the origin of the C3-Tag cells by the detection of SV40 large T antigen (Supplemental Figure 4A). Similar to the human breast cancer cell lines, EPO did not affect proliferation (Figure 2, B and C) or chemotherapy-induced apoptosis (Figure 2, D and E) of these primary murine cell lines despite expressing detectable EPO-R 
A
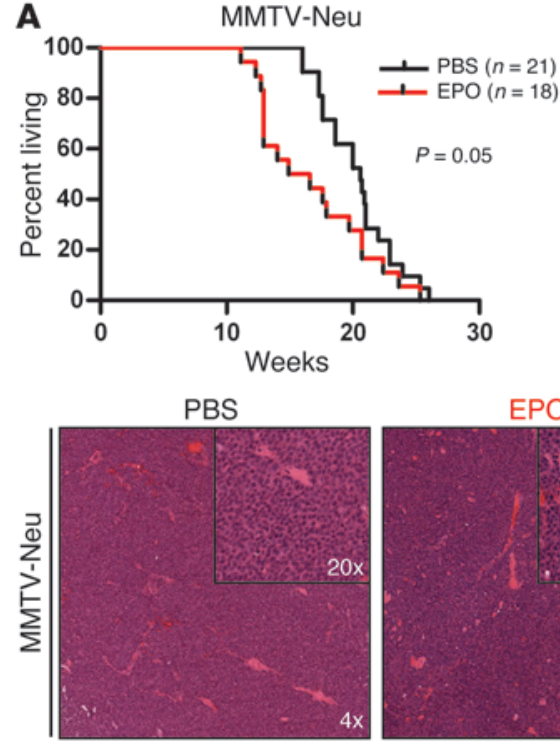

B

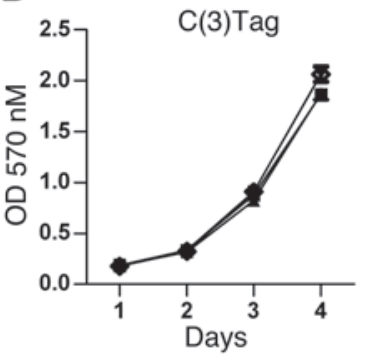

D

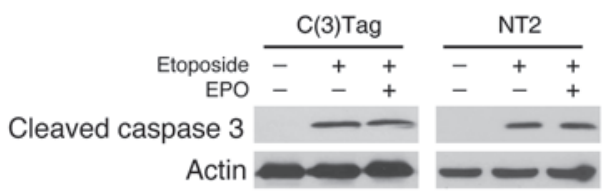

EPO
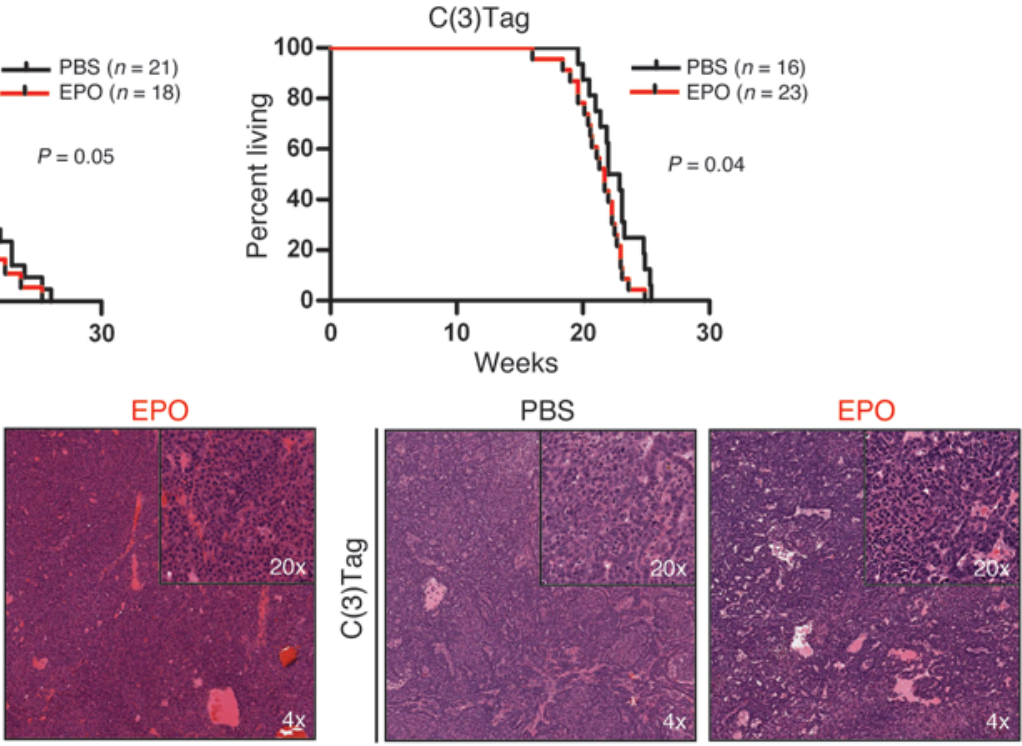

C
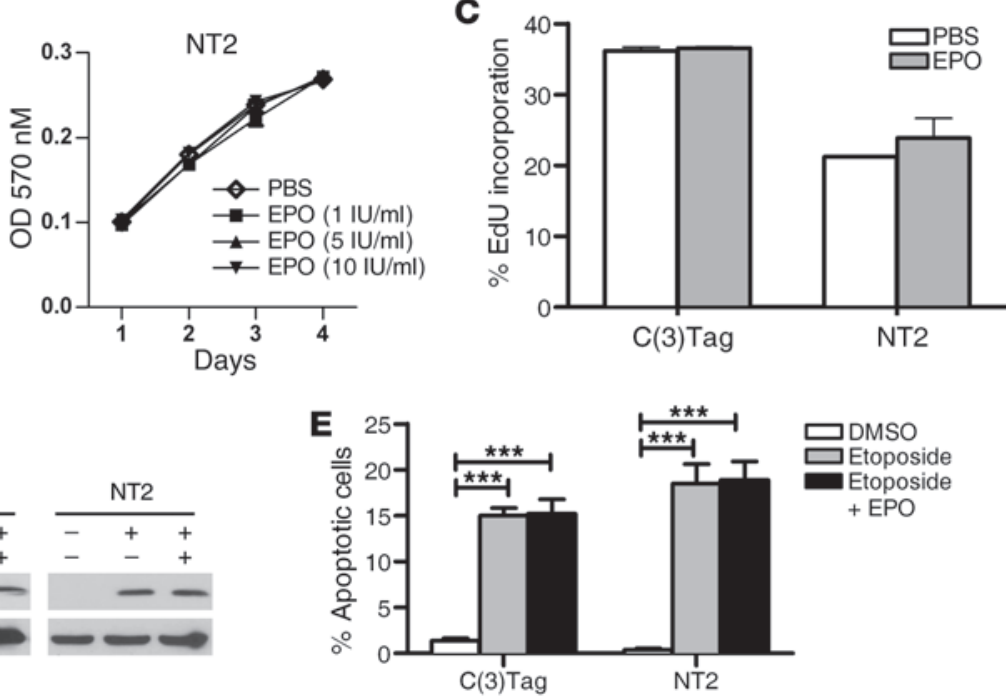

Figure 2

EPO decreases the percentage of breast cancer GEMMs living over time yet does not affect breast cancer GEMM cell lines in vitro. (A) KaplanMeier survival curves of MMTV-Neu and C3-Tag mice randomized to saline or EPO (500 IU/kg BIW) injections. (MMTV-Neu: $P=0.05$, C3-Tag: $P=0.04)$. Tumors were sectioned and H\&E stained. (B) Indicated cell lines were cultured in the presence of increasing concentrations of EPO $(1,5$, and $10 \mathrm{IU} / \mathrm{ml}$, replenished to the culture every other day). and proliferation was detected by MTT assay. (C) Cell lines were cultured in the presence of PBS or EPO (1 IU/ml) for 16 hours and EdU for 1 hour. They were then analyzed for EdU incorporation by flow cytometry. (D) Indicated cell lines were treated with vehicle, etoposide $(50 \mu \mathrm{M})$, or etoposide $(50 \mu \mathrm{M})$ and EPO $(10 \mathrm{lU} / \mathrm{ml})$ for 24 hours. Whole cell extracts were western blotted with the indicated antibodies. (E) Indicated cell lines were treated with DMSO, etoposide (50 $\mu \mathrm{M})$, or etoposide $(50 \mu \mathrm{M})$ and EPO (10 IU/ml) for $24 \mathrm{hours}$. Percentage of apoptotic cells was then determined by flow analysis using Alexa Fluor 488 annexin V/PI Cell Apoptosis Kit (Invitrogen). ${ }^{* * \star} P \leq 0.001$.

(Supplemental Figure 4B). Thus, while EPO is protumorigenic in vivo, it did not affect proliferation or apoptosis of C3-Tag and MMTV-Neu cell lines in vitro.

EPO increases the growth of orthotopically implanted C3-Tag and $M M T V-N e u$ tumors. We next asked whether orthotopic reimplantation of luciferase-expressing C3-Tag cells [C3-Tag-luc] into the mammary fat pad would affect the cell's sensitivity to exogenous EPO. To this end, C3-Tag-luc cells were orthotopically implanted into syngeneic female FVB/N mice. EPO significantly increased tumor burden at 21 days as measured by Xenogen IVIS $(P \leq 0.05$;
Figure 3, A and B) and caliper measurements (Supplemental Figure 5A) and was associated with the more rapid growth of established tumors (Supplemental Figure 5B) and a significantly decreased percentage of mice living over time $(P=0.005$, Supplemental Figure 5C). Exogenous EPO also promoted the growth of NT2 cells orthotopically implanted into FVB mice (Figure 3C).

Finally, exogenous EPO decreased the percentage of mice alive that had been tail-vein injected with C3-Tag cells (an experimental model of metastases) (Figure 3D) as well as C3-Tag tail-veininjected mice concurrently treated with carboplatin (Figure 3E). 
A

PBS
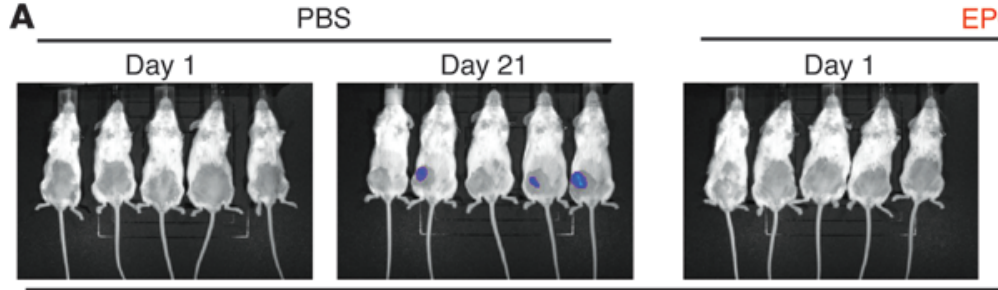

EPO

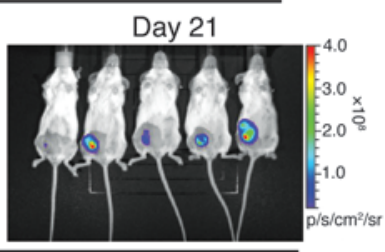

Image

Min $=1.38 \times 10^{5}$ $\operatorname{Max}=1.15 \times 10^{8}$

C(3)Tag-luc cells
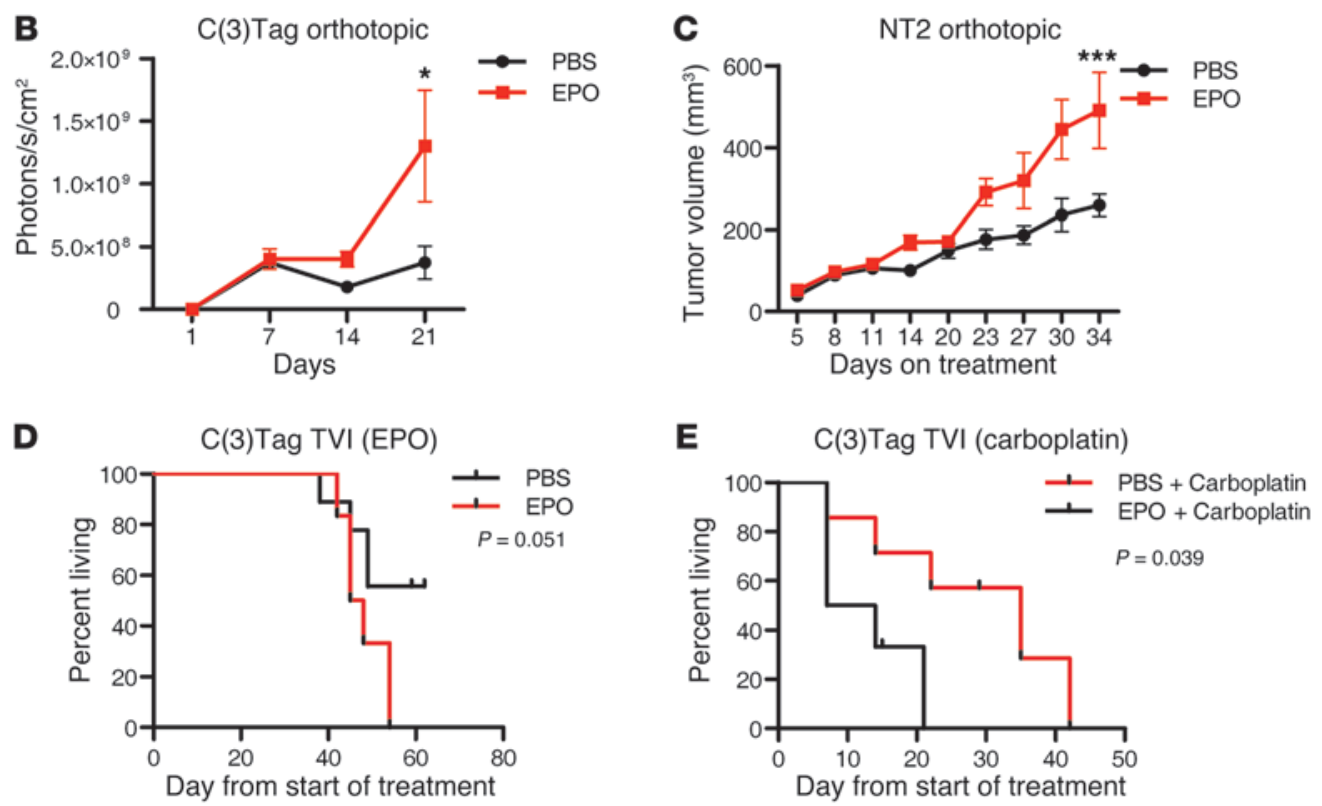

Figure 3

EPO promotes progression of orthotopic C3-Tag and MMTV-Neu tumors. (A) $1 \times 10^{5}$ luciferase-expressing C3-Tag cells were implanted into the mammary fat pads of FVB/N mice. The mice were randomized to receive PBS or EPO (500 IU/kg BIW). Representative Xenogen images of mice on day 1 and day 21 after injection. (B) Living Image software (Caliper Life Sciences) was used to quantify luciferase activity of orthotopic C3-Tag tumors. Mean photons $/ \mathrm{s} / \mathrm{cm}^{2}$ is graphed with error bars representing SEM. ${ }^{*} P \leq 0.05$ on day 21 . (C) Tumor volume of orthotopically implanted NT2 cells as measured by calipers. ${ }^{* * *} P \leq 0.001$. ( $\mathbf{D}$ and $\mathbf{E}$ ) Kaplan-Meier curves of percentage of C3-Tag tail vein-injected mice alive in the indicated treatment groups.

Thus, orthotopic implantation of C3-Tag or MMTV-Neu cells and metastatic C3-Tag models recapitulate the in vivo EPO responsiveness of autochthonous GEMM tumors.

EPO increases mammosphere formation and promotes self-renewal. We hypothesized that EPO's tumor promoting effects are seen in vivo but not with in vitro assays because it affects a limited fraction of cells, such as breast TICs. Thus, its effects might only be seen with a longer period of EPO administration, such as those achieved in vivo. We hypothesized that if we enriched for the EPO-responsive fraction of cells, we might be able to see its protumorigenic effects more rapidly. Therefore, we compared the impact of exogenous EPO on the ability of FACS-sorted (Supplemental Figure 6) subpopulations of SUM149 cells: (a) CD $44^{+} \mathrm{CD} 24-\mathrm{EpCAM}^{+}$[TICs], (b) $\mathrm{CD}_{4}{ }^{+} \mathrm{CD} 24-\mathrm{EpCAM}^{-}$(non-TICs), and (c) CD $44^{+} \mathrm{CD} 24^{+} \mathrm{EpCAM}^{+}$) non-TICs) to form mammospheres in vitro (Figure 4, $A$ and $B$, and ref. 35). EPO significantly increased the number of spheres in the TIC fraction (Figure 4, A and B), but not in unsorted SUM149 cells or SUM149 cells from non-TIC fractions.

Furthermore, to determine the effects of EPO on breast TIC self renewal, PBS- and EPO-treated spheres were dissociated and passaged for several generations. EPO-treated spheres had a higher sphere-forming efficiency and maintained a steady level of sphereforming activity over serial passage (Figure 4C). In contrast, PBStreated spheres had a progressive decrease in the capacity to form daughter spheres, with a significantly lower sphere-forming efficiency by passage 4 . Thus, stringent isolation of breast cancer cell populations revealed that the effects of EPO are remarkably specific in breast cancer in vitro, promoting the self renewal of a highly tumorigenic TIC fraction.

EPO promotes expansion of breast TICs in MMTV-Wnt1 breast tumors. Previous studies have defined TICs from the autochthonous breast tumors of MMTV-Wnt1 mice (36). In keeping with the results in SUM149 cells, in vitro exposure to exogenous EPO appeared to increase sphere formation by MMTV-Wnt1 TICs (Lin-Thy $1^{+} \mathrm{CD} 24^{+}$) (Figure 4, D and E). We next wanted to see whether EPO can promote the expansion of breast TICs in vivo as well. To this end, we randomized female $\mathrm{FVB} / \mathrm{N}$ mice with orthotopically implanted $M M T V$-Wnt 1 tumors to PBS or EPO treatment (Figure 4F). After 4 weeks, the percentages of MMTV-Wnt1 TICs quantified by flow cytometry (Supplemental Figure 7A) were significantly higher in the tumors of mice that received EPO (Figure 4G and Supplemental Figure 7B). Moreover, cells from EPO-treated tumors showed 
A

SUM149

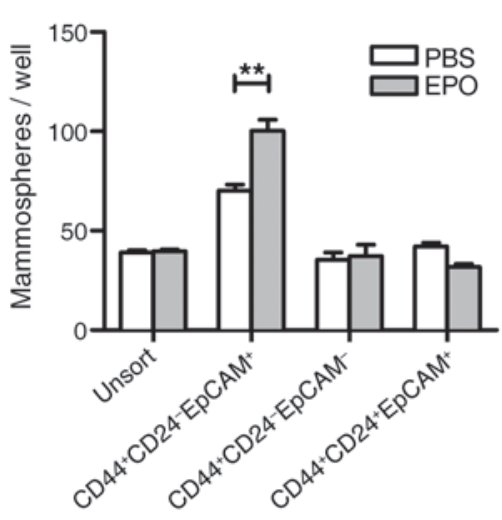

B

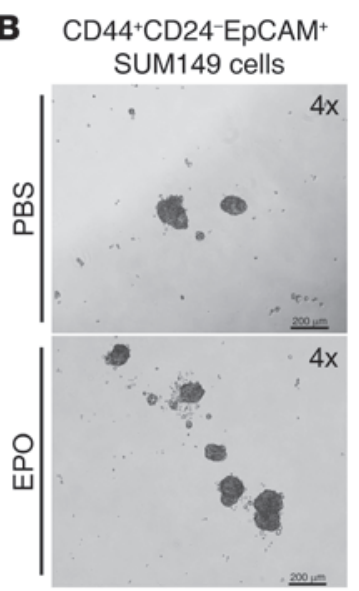

C

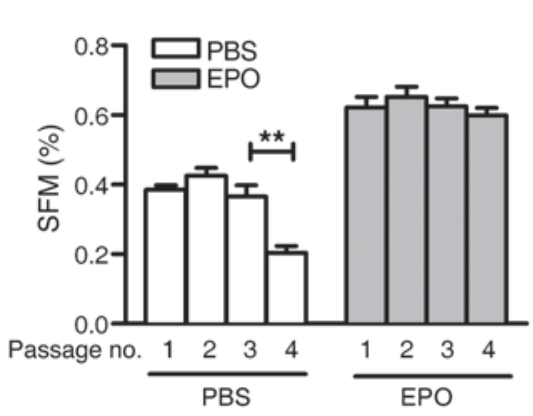

D
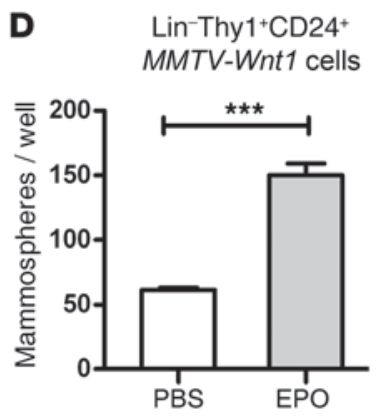

E $\quad$ Lin-Thy $1^{+} \mathrm{CD} 24^{+}$ MMTV-Wnt1 cells

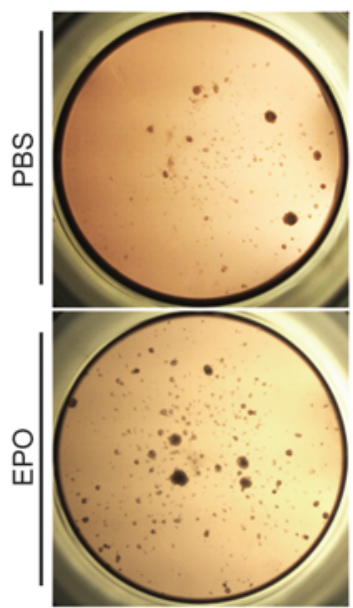

$\mathbf{F}$

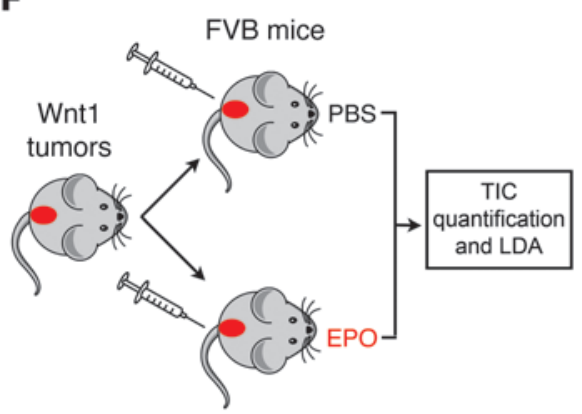

G

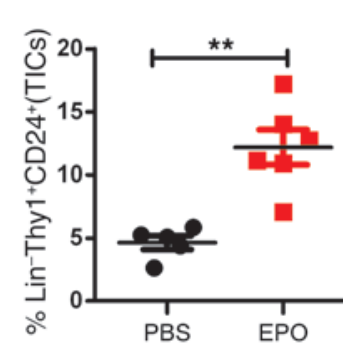

\section{Figure 4}

EPO promotes mammosphere formation, TIC self renewal, and expansion of TICs in vivo. (A) Mammosphere formation of FACS-sorted SUM149 cells. 20,000 cells from each subpopulation were plated in triplicate in 6-well plates. PBS or EPO (1 IU/ml) were added every other day, and colonies $(\geq 50 \mu \mathrm{m}$ ) were counted on day 5. (B) Representative photos of mammospheres from PBS- or EPO-treated SUM149 cells. Scale bars: $200 \mu \mathrm{m}$. (C) Primary mammospheres from SUM149 TICs (CD44+CD24-EpCAM+) were dissociated and serial passaged by replating 20,000 cells for each passage. TICs cultured in PBS showed a significant exhaustion of self-renewal capacity after passage 3. (D) Mammosphere formation of Lin-Thy ${ }^{+}$CD24 ${ }^{+}$MMTV-Wnt1 cells cultured with PBS or EPO under $21 \% \mathrm{O}_{2}$. Non-Lin-Thy ${ }^{+}$CD24+ cells did not grow spheres. (E) Representative photos of spheres from Lin-Thy1+CD24+ MMTV-Wnt1 cells treated with PBS or EPO. Original magnification, $\times 1$. (F) Schematic of orthotopically implanted MMTV-Wnt1 tumors treated with PBS or EPO (500 IU/kg i.p. twice a week) for 4 weeks then assessed for TIC frequency by flow cytometry and LDA. (G) MMTV-Wnt1 orthotopic tumors were harvested and stained with antibodies specific to Thy1, CD24, a lineage cocktail, and DAPI. There were a significantly higher percentage of Lin - Thy ${ }^{+} \mathrm{CD} 24^{+}$cells in tumors of mice treated with EPO. ${ }^{* \star} P \leq 0.01 ;{ }^{* * *} P \leq 0.001$.

increased tumor- initiating capacity by in vivo limiting dilution assays (Table 1) (tumor initiating frequency: PBS, 1 in 2,166 [95\% CI of 1,205-3,896]; EPO, 1 in 673 [95\% CI of 435-1,041]). These results in aggregate demonstrate that exogenous EPO promotes the expansion and self-renewal of breast TICs in vitro and in vivo.

EPO stimulates JAK/STAT signaling in breast TICs. EPO activates the JAK/STAT pathway in hematopoietic erythroid precursors, and recent work has shown that $\mathrm{CD} 44^{+} \mathrm{CD} 24^{-}$stem cell-like breast cancer cells require JAK2/STAT3 signaling for growth (37). We therefore asked whether exogenous EPO activates JAK/STAT signaling in breast TICs. We noted that SUM149 TICs had higher levels of EPO-R (Supplemental Figure 8) and higher basal levels of JAK/STAT activation, as evidenced by increased PSTAT3 in
PBS-treated TICs relative to PBS-treated non-TICs (Figure 5A). In addition, EPO-treated TICs had induction of PJAK2 and PSTAT3, while EPO-treated non-TICs did not (Figure 5A).

Additionally, JAK/STAT activation in breast TICs resulted in changes in STAT-responsive genes, as microarrays performed on SUM149 TICs cultured overnight in the presence of EPO showed an enrichment of JAK/STAT gene signatures as well as gene signatures that characterize cancer stem cells or promote stem cell self renewal, such as the notch and hedgehog pathways (Figure 5B). Therefore, treatment of breast TICs with exogenous EPO not only upregulates JAK/STAT signaling but also induces functional gene expression changes indicative of STAT, hedgehog, and notch transcriptional activation. 


\begin{abstract}
Table 1
EPO promotes expansion of tumor-initiating capacity of breast TICs from MMTV-Wnt1 tumors
\end{abstract}

\begin{tabular}{lcccccc} 
Cells injected & $\mathbf{2 , 0 0 0}$ & $\mathbf{1 0 0 0}$ & $\mathbf{5 0 0}$ & $\mathbf{2 5 0}$ & $\mathbf{1 0 0}$ & TIC capacity \\
PBS treated & $5 / 6$ & $3 / 10$ & $2 / 12$ & $1 / 13$ & $0 / 6$ & 1 in $2,166\left(1,205-3,896^{A}\right)$ \\
EPO treated & $6 / 6$ & $8 / 10$ & $6 / 12$ & $3 / 13$ & $1 / 6$ & 1 in $673\left(435-1,041^{A}\right)$ \\
\hline
\end{tabular}

A95\% Cl. Cells dissociated from PBS- or EPO-treated MMTV-Wnt1 orthotopic tumors were injected into the mammary fat pads of female FVB mice at the indicated cell numbers. Tumorinitiating capacity and $\mathrm{Cls}$ (95\%) were calculated using L-Calc limiting dilution software 7 weeks after inoculation.

$E P O$ expression in primary tumors correlates with clinical outcome.

While EPO is primarily produced in the kidney, a number of other tissues, a broad spectrum of cancer cell lines, and primary tumors have also been shown to produce EPO $(6,7,42-44)$. We found that endogenous EPO was hypoxia inducible in breast cancer cell lines (Figure 6, B and C), but not human mammary epithelial cells (HMECs). Additionally, we examined several of the cellular compartments within breast tumors for their ability to produce endogenous

Neutralizing antibodies to EPO or EPO-R abrogate bypoxia-induced mammosphere formation. Hypoxia is known to increase TIC selfrenewal, and EPO is a well-established hypoxia-inducible gene (38). To determine the contribution of endogenous EPO to hypoxia-induced mammosphere formation, we assessed sphere formation of SUM149 TICs in the presence of increasing concentrations of neutralizing antibodies to EPO, 2 independent EPO-R antibodies, or control antibody (anti-HA) (Figure 5, C and D). Both EPO and EPO-R neutralizing antibodies decreased EPO-induced ERK activation (Supplemental Figure 9) as well as hypoxia-induced mammosphere formation (Figure 5, C and D), suggesting that endogenous EPO and EPO-R signaling are necessary for the hypoxia-induced clonogenicity of breast TICs.

JAK2 inhibition abrogates EPO-induced mammosphere formation and is synergistic with chemotherapy in vivo. Exogenous EPO treatment of breast TICs promotes mammosphere formation (Figure 4, A-E) and JAK/STAT activation (Figure 5, A and B). We asked whether pharmacologic JAK2 inhibition using the orally available JAK2 kinase inhibitor TG101348 (TargeGen) (39) inhibits sphere formation. In keeping with the notion that JAK2 signaling is critical for mammosphere formation by breast TICs, we saw a dose-dependent reduction in sphere formation by TG101348 (Figure 5E).

While JAK2 inhibition may be effective at limiting breast TIC self-renewal (Figure 5E), the lack of JAK2 activation in the nonTICs suggested that it may not be effective on this population of cells. We therefore hypothesized that combining JAK2 inhibition with chemotherapy might be necessary to target TICs and non-TICs, respectively. In keeping with this notion, orthotopic Wnt 1 tumors treated with the combination of carboplatin and TG101348 had a statistically significant decrease in tumor volume relative to vehicle treatment, treatment with single-agent carboplatin, or treatment with single-agent TG101348 (Figure 5F). Moreover, the addition of TG101348 to carboplatin did not appear to induce significantly more anemia (the primary dose-limiting toxicity of JAK2 inhibition) (Figure 5G). Therefore, the combination of chemotherapy with JAK2 inhibition appears to have potential for the treatment of breast cancer.

Endogenous EPO correlates negatively with relapse-free survival and is expressed by breast cancer cells and tumor-associated endothelial cells. We hypothesized that endogenous EPO exists in the tumor microenvironment and that EPO levels might therefore correlate with the clinical outcome of women with breast cancer. We interrogated 2 independent microarray data sets of early stage breast cancers (GEO GSE18229 and GSE26338) $(40,41)$ and found that high EPO expression was significantly associated with a decreased probability of relapse (Figure 6A) as well as enrichment in STAT gene signatures (Supplemental Figure 10). Thus, endogenous
EPO and found that RNA from laser-captured, tumor-associated endothelial cells had higher levels of EPO than endothelial cells from adjacent normal tissue (Figure 6D and ref. 45). However, primary cultures of cancer associated fibroblasts (CAF) from human breast tumors of luminal (CAF9) and basal-like (CAF7J) breast cancers did not have appreciable hypoxia-inducible EPO mRNA or protein when cultured under hypoxia (Supplemental Figure 11, A and B), nor did HUVECs (Figure 6E). In aggregate, these data enforce the notion of the biologic complexity of tumors and suggest that both breast cancer cells and tumor-associated endothelial cells may produce EPO and that increased $E P O$ expression correlates with shortened relapse-free survival in breast cancer.

\section{Discussion}

rHuEPO was developed with the best of intentions. While it decreases the transfusion requirements and improves the quality of life of cancer patients, randomized trials have demonstrated that $\mathrm{rHuEPO}$ administration is associated with shorter progression-free and overall survival (11-17). A more definitive understanding of how EPO is protumorigenic is important. First, it would allow the design of novel ESAs that promote erythropoiesis but not tumorigenicity. Second, it might define whether all patients or only specific subgroups should be excluded from ESA use. Finally, it may give us insight into the role that endogenous EPO plays in tumor progression. Efforts to assess the protumorigenic effects of EPO have been particularly hampered by the lack of in vivo models to test hypotheses. Our experiments identify relevant GEMMs of breast cancer in which autochthonous breast tumors are sensitive to the growth-promoting effects of EPO and are sensitive to JAK/STAT inhibition.

Recent data from a loss-of-function screen identified the JAK2/ STAT3 pathway as being necessary for the growth of basal-like, stem-like breast cancer cells and suggested that IL- 6 was the primary mediator of normoxic JAK/STAT signaling (37). Notably however, breast TICs were never enriched for in this study, and therefore their data were derived primarily from comparisons of basal-like with luminal breast cancer cell lines. Our experiments therefore refine and extended these observations via a functional analysis of the effects of JAK/STAT signaling in a highly enriched population of TICs (the CD $44^{+} \mathrm{CD} 24-\mathrm{EpCAM}^{+}$fraction) (35) and identify EPO as a hypoxia-induced activator of JAK/STAT signaling and cancer cell stemness. Along these lines, a previous report also demonstrated that EPO increased the numbers and self renewal of breast cancer-initiating cells (CICs), yet in contrast to our studies, identified notch, rather than the JAK/STAT pathway, as a key regulator of self renewal (46). 
A

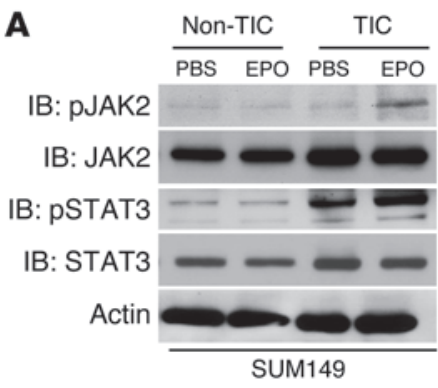

C

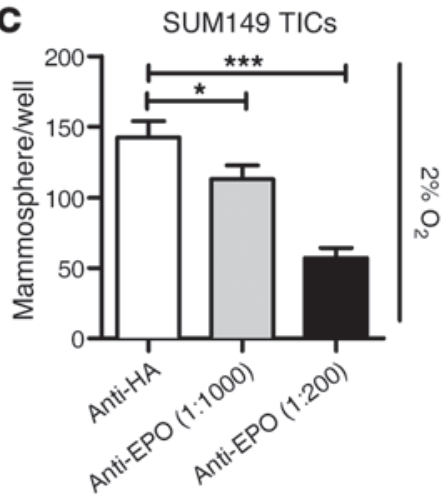

F

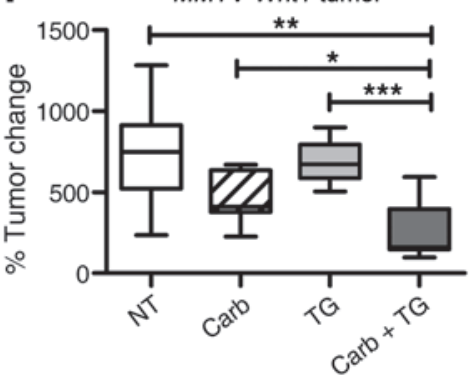

B

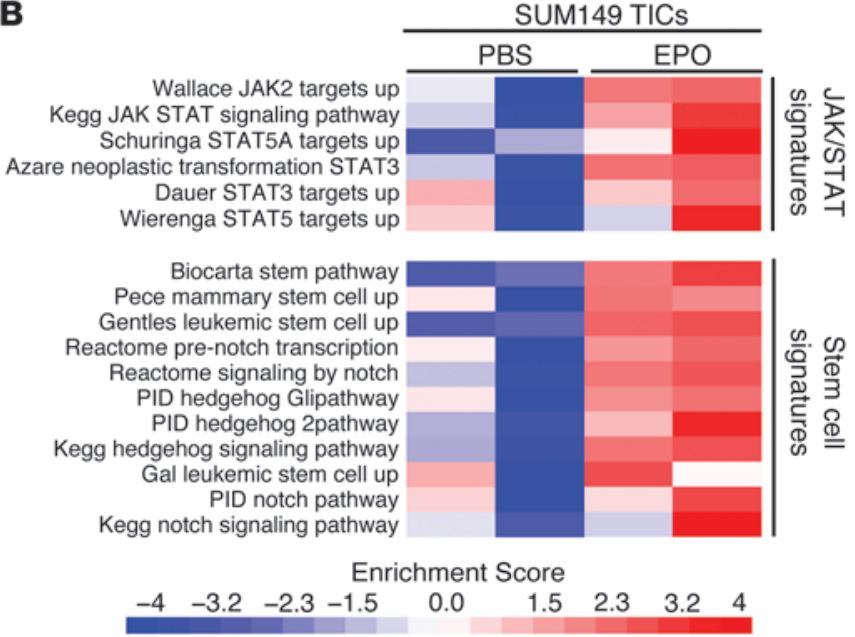

D
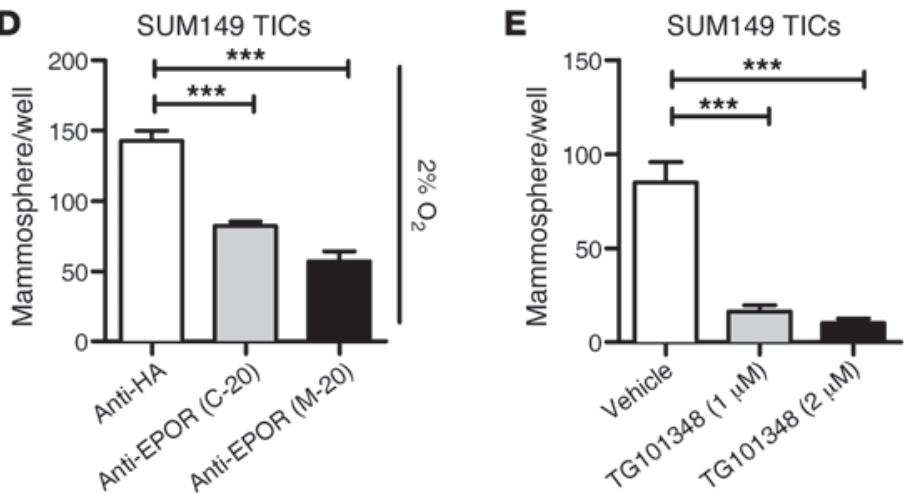

G

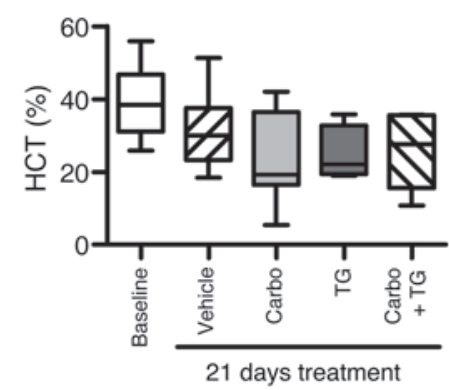

Figure 5

EPO activates JAK/STAT signaling in breast TICs, and JAK inhibition is a potential therapeutic target in breast cancer. (A) SUM149 cells were FACS sorted into TIC (CD44+CD24-EpCAM ${ }^{+}$) and non-TIC (not CD44+CD24-EpCAM+) populations, treated with PBS or EPO (1 IU/ml) for 10 minutes, and immunoblotted with the indicated antibodies. (B) Gene-expression profiles were generated from total RNA of sorted SUM149 TICs $\left(\mathrm{CD} 44^{+} \mathrm{CD} 24-\mathrm{EpCAM}\right)$, treated with PBS or EPO $(1 \mathrm{lU} / \mathrm{ml})$ for 16 hours, and subjected to ssGSEA for the indicated JAK/STAT and cancer stem cell gene signatures. (C) Mammosphere formation of CD44+CD24-EpCAM+SUM149 cells cultured at hypoxia $\left(2 \% \mathrm{O}_{2}\right)$ in the presence of control antibody (anti-HA) or anti-EPO antibody at the indicated dilutions. (D) Mammosphere formation of CD44+CD24-EpCAM+ SUM149 cells cultured at hypoxia $\left(2 \% \mathrm{O}_{2}\right)$ in the presence of control antibody (anti-HA) or 2 indicated anti-EPOR antibodies (1:200). (E) 20,000 (CD44+CD24-EpCAM $\left.{ }^{+}\right)$ SUM149 cells were plated in duplicate in the presence of EPO $(10 \mathrm{lU} / \mathrm{ml})$ and vehicle or EPO and the JAK inhibitor TG101348 at the indicated concentrations. Spheres were counted on day 5. (F) Orthotopic MMTV-Wnt1 tumors were grown to $5 \mathrm{~mm}$ in length and width (average tumor volume of all groups $=60 \mathrm{~mm}^{3}$ ) and treated with vehicle (NT), carboplatin (Carbo), TG101348 (TG), or the combination of carboplatin and TG101348. Caliper measurements were taken weekly. ${ }^{*} P \leq 0.05 ;{ }^{* *} P \leq 0.01 ;{ }^{* \star} P \leq 0.001$. (G) Hematocrit (HCT) measurements were done at baseline and at end point in the indicated treatment groups. 
A

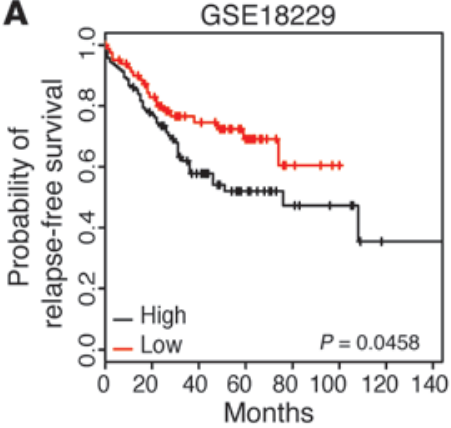

C

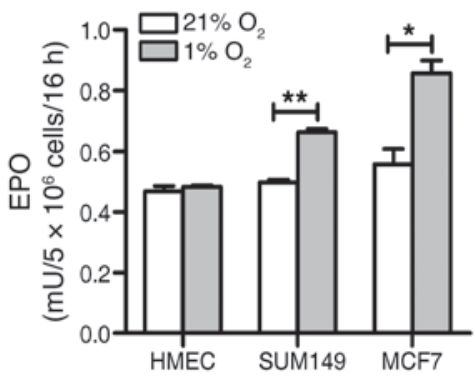

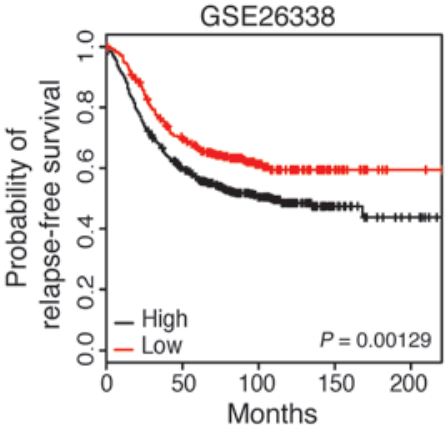

D

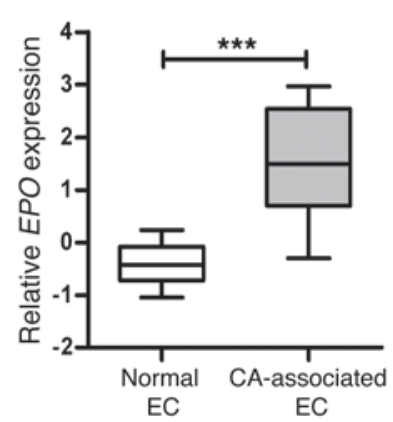

B Cell line EPO mRNA

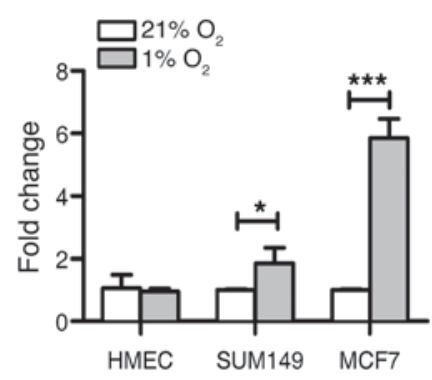

E HUVEC

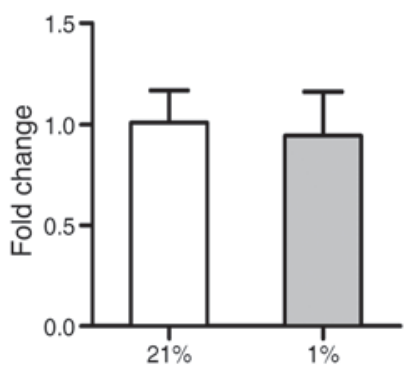

Figure 6

Endogenous EPO expression correlates negatively with relapse-free survival and is produced by breast cancer cell lines and tumor endothelial cells. (A) Breast tumors (337 patients [GSE18229] and 855 patients [GSE26338] were rank ordered based on their EPO expression and divided into those with high and low EPO expression (high: top 2 tertiles, low: bottom tertile). $P=0.0088$ for UNC337, $P=0.0012$ for GSE26338, log rank test. (B) EPO mRNA levels from HMECs and the indicated breast cancer cell lines cultured in $21 \%$ and $1 \% \mathrm{O}_{2}$ using TaqMan quantitative RT-PCR. (C) EPO protein as measured by ELISA on conditioned medium from the indicated cell lines after culture under $21 \% \mathrm{O}_{2}$ or $1 \% \mathrm{O}_{2}$ for 16 hours. (D) Microarray gene expression for EPO was abstracted from a publically available data set (GSE7413) in which breast cancer-associated endothelial cells or endothelial cells from adjacent normal were laser capture microdissected. Relative gene expression Cy5 (tumor)/Cy3(reference) is shown. (E) EPO mRNA levels from HUVECs cultured in $21 \%$ and $1 \% \mathrm{O}_{2}$ were measured by TaqMan quantitative PCR. ${ }^{*} P \leq 0.05 ;{ }^{* \star} P \leq 0.01 ;{ }^{* \star \star} P \leq 0.001$.

A recent report suggests that EPO antagonizes treatment with the anti-HER2 antibody trastuzumab by activating EPO-R/JAK2 downstream effectors, effectively bypassing HER2 signaling (47). While mechanistically satisfying, this result only explains the therapeutic antagonism between EPO and trastuzumab in women with HER $2^{+}$breast cancer, which represents approximately $15 \%-20 \%$ of patients. Moreover, it should result in therapeutic antagonism only in women being actively treated with anti-HER2 agents. The fact that EPO's negative effects have been seen in a wide variety of tumor types and in anemic cancer patients not undergoing treatment argue strongly that there are other, non-HER2-related ways in which EPO promotes tumor progression $(17,48)$. These clinical studies along with our data in both the C3-Tag and MMTV-Neu GEMMs are strong evidence that the negative effects of EPO are not merely a result of therapeutic antagonism to trastuzumab.

Finally, our studies support a role for endogenous EPO in breast tumorigenesis. Our studies suggest that both breast cancer cells and cancer-associated endothelial cells are potential sources of intratumoral EPO (Figure 7). While we did not see appreciable hypoxia-inducible EPO expression from CAFs, others have reported that tumor-associated stromal cells are a source of PDGF-dependent EPO production (49). Nonetheless, hypoxiadependent breast TIC self renewal is dependent upon EPO and is correlated with relapse-free survival in breast cancer patients. Moreover, we identify the therapeutic potential of combining the
JAK2 inhibitor TG101348 with carboplatin chemotherapy in vivo and postulate that this synergistic effect was seen because of the ability of TG101348 and carboplatin to target the TIC and bulk populations of breast cancer cells, respectively. This is particularly interesting in light of the fact that the JAK2 inhibitor ruxolitinib (Jakafi), is now FDA approved for the treatment of patients with JAK2 mutant myelofibrosis, and clinical trials using ruxolitinib are ongoing in women with breast cancer.

In summary, we have identified tractable GEMMs of breast cancer in which autochthonous tumors are sensitive to the protumorigenic effects of EPO. EPO promotes self-renewal and enhances TIC expansion of breast TICs in vitro and in vivo. Finally, our studies define an active role for endogenous EPO produced within tumors and show that JAK2 inhibition in combination with chemotherapy is a promising therapeutic strategy in the treatment of breast cancer.

\section{Methods}

Cell culture. MDA-MB231, SKBR3, and MCF7 cell lines were obtained from ATCC and cultured according to their recommendations. SUM149 cells (Asterand) were maintained in HuMEC basal medium and supplements (Gibco; Life Technologies) and 5\% FBS and $100 \mathrm{U} / \mathrm{ml}$ penicillin/streptomycin. HMEC cells (50) were cultured in HuMEC ready medium (Gibco; Life Technologies). The C3-Tag cell line was established by dissociation of C3-Tag mammary tumors with $0.25 \%$ Trypsin, followed by differential trypsinization to remove fibroblasts. C3-Tag-luc cells were generated by stably trans- 


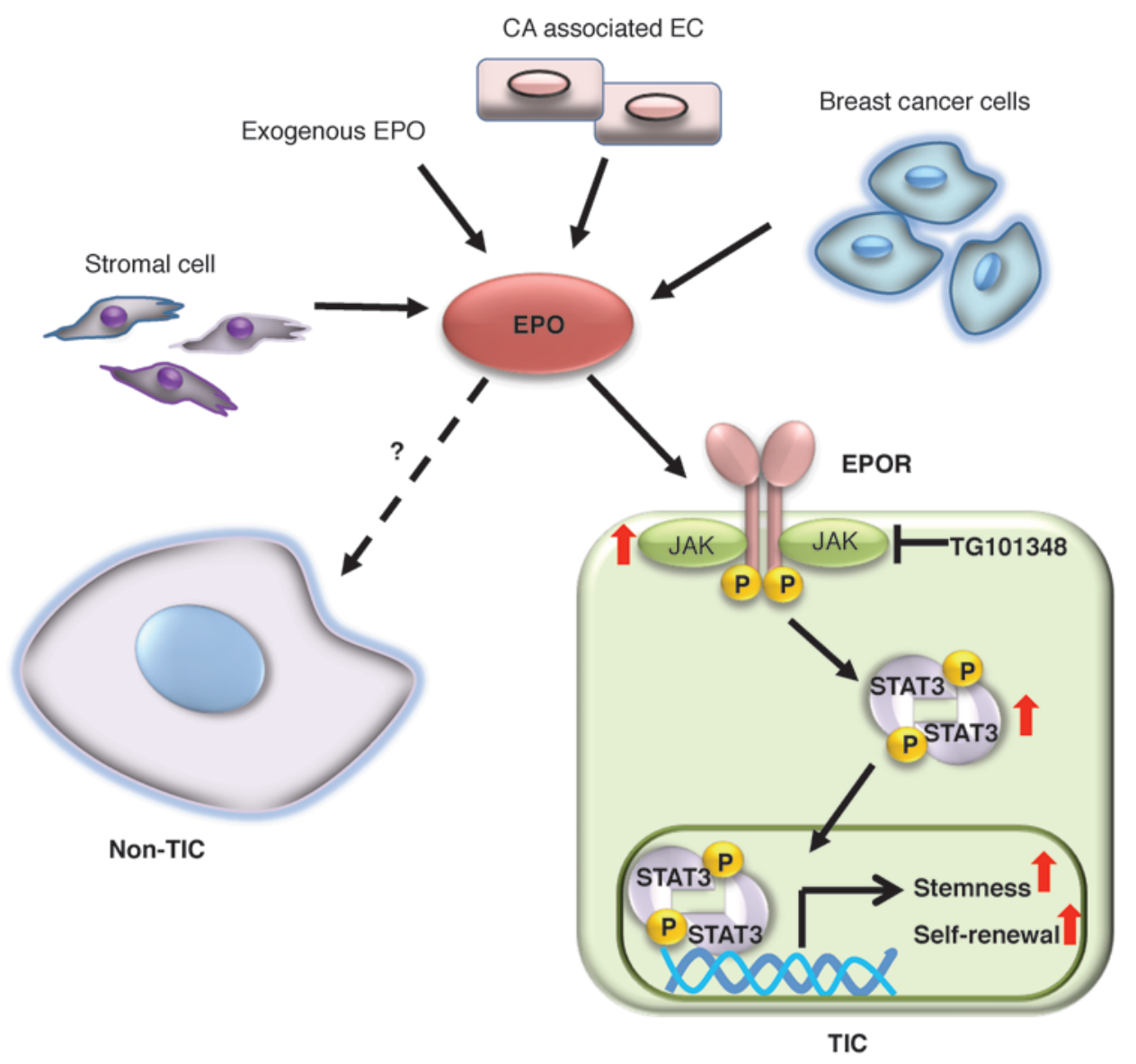

\section{Figure 7}

Sources of EPO and proposed mechanism of EPO-promoting breast TIC self renewal. Intratumoral EPO may be derived from several intratumoral cells including stromal cells, cancer-associated endothelial cells, and breast cancer cells as well as exogenous administration. Intratumoral EPO activates EPO-R present on breast TICs that subsequently activates JAK/STAT signaling promoting TIC self renewal and stemness. Potential effects of EPO on the non-TIC fraction will need to be investigated. The JAK inhibitor TG101348 inhibits JAK/STAT signaling and EPO-dependent breast TIC self renewal. ducing C3-Tag cells with retrovirus expressing pMMP-Luc-Neo construct. C3-Tag cells were maintained in DMEM (Cellgro) with $10 \%$ FBS and $1 \%$ penicillin/streptomycin. All cell lines were grown at $37^{\circ} \mathrm{C}$ and $5 \% \mathrm{CO}_{2}$. The NT2 cell line was provided by Jonathan Serody (University of North CarolinaChapel Hill [UNC-CH]) and Elizabeth Jaffee (Johns Hopkins University).

Cell staining and flow cytometry. Quantification of apoptosis of the cell lines was performed by staining for annexin $\mathrm{V}$ and propidium iodide (PI). Cells were treated with vehicle, etoposide $(50,100 \mu \mathrm{M})$, or etoposide in combination with EPO $(10 \mathrm{IU} / \mathrm{ml})$ for 12 hours in serum-free medium. Percentage of apoptotic cells was determined by flow analysis using the Alexa Fluor 488/annexin V/PI Cell Apoptosis Kit (Invitrogen) according to the manufacturer's instructions. Cell-cycle analysis of vehicle-treated or EPO-treated $(10 \mathrm{IU} / \mathrm{ml})$ cells was performed by EdU incorporation using Click-iT EdU Alexa Fluor 647 Flow Assay Kit (Invitrogen) according to the manufacturer's instructions.

Flow cytometry to enrich for breast TICs was performed as previously described $(35,36)$. Briefly, cells were stained at a concentration of $1 \times 10^{6}$ cells per $100 \mu \mathrm{l}$ of HBSS with $2 \%$ FBS. Fluorescent-conjugated antibodies (Supplemental Table 1) at appropriate dilutions were added. Cells were stained for 30 minutes on ice, washed with staining medium, and resuspended in staining medium containing DAPI (final concentration, $1 \mu \mathrm{g} / \mathrm{ml}$ ). Multi-color flow cytometry was performed on a CyAnTM ADP flow cytometer (Dako), and data analysis was performed using FlowJo software (Tree Star Inc.). A portion of double-sorted cells was reanalyzed to ensure purity. Final cell purity was greater than $95 \%$.

Western blot analysis. Cells were washed twice with PBS and harvested in RIPA lysis buffer. Protein concentration was determined with Bio-Rad protein assay, and $20 \mu \mathrm{g}$ of whole-cell lysates was used for SDS-PAGE. Membranes were blocked with $5 \%$ milk or BSA diluted in $1 \times$ TBST for 1 hour and incubated at $4{ }^{\circ} \mathrm{C}$ overnight with one of the following primary antibodies: phospho-Jak2 (Tyr1007/1008) (cat. \#3771:1:1000; Cell Signaling Technology), Jak2 (D2E12) (cat. \#3230, 1:1000; Cell Signaling Technology), phospho-Stat3 (Tyr705) (cat. \#9145, 1:1000; Cell Signaling Technology), cleaved caspase 3 (cat. \#9662, 1:1000; Cell Signaling Technology), and Stat3 (cat. \#8768; Cell Signaling Technology). Immunoblots against actin (sc-1615, 1:5000; Santa Cruz Biotechnology Inc.) were used as loading controls. The membranes were then probed with secondary antibodies (HRP-conjugated goat anti-rabbit and goat anti-mouse, cat. \#31462 and \#31432, respectively, 1:5000; Thermo Scientific), and immunoreactions were detected with Amersham Biosciences ECL (GE Healthcare).

EPO ELISA. Five million cells were plated in $10 \mathrm{~cm}$ dishes in $6 \mathrm{ml}$ of serum-free medium and cultured under either normoxia $\left(21 \% \mathrm{O}_{2}\right)$ or hypoxia $\left(1 \% \mathrm{O}_{2}\right)$ for 16 hours. Media were then collected and concentrated to $200 \mu \mathrm{l}$ using Ultra-15 centrifugal filter units (cut-off $10 \mathrm{kDa}$; Millipore). EPO levels were assayed in duplicate using a human ELISA kit (Stem Cell Technologies) following the manufacturer's instructions.

Total RNA Isolation and real-time quantitative PCR. Total RNA was isolated using the RNAeasy Mini Kit (QIAGEN Sciences) following the manufacturer's instructions. One microgram of purified total RNA was used for reverse transcription with ImProm-11 Reverse Transcription System (Promega) according to the manufacturer's instructions. Expression of all transcripts was determined by using commercially available assays from Applied Biosystems. Transcript expression levels of human EPO (HS01071097), 18S ribosomal RNA (Hs03003631) and GAPDH 
(Hs0392909), and relative gene expression were calculated according to the $2^{-\Delta \Delta \mathrm{Ct}}$ method, as previously described (51).

Mammosphere assay. Mammosphere assays were performed according to the protocol from StemCell Technologies. Briefly, 20,000 sorted or unsorted SUM149 cells per well were grown in 6-well Ultra Low Attachment Plates (Corning) in $2 \mathrm{ml}$ of Complete MammoCult Medium (MammoCult Basal Medium supplied with $10 \%$ Mammocult proliferation supplement, $4 \mu \mathrm{g} / \mathrm{ml}$ heparin, and $0.48 \mu \mathrm{g} / \mathrm{ml}$ hydrocortisone; all purchased from StemCell Technologies). EPO was added (10 IU/ml) every other day, and spheres (size $\geq 50 \mu \mathrm{m}$ ) were counted on day 5 .

EPO neutralization experiments were performed using anti-EPO antibody (H-162: sc-7956; Santa Cruz Biotechnology Inc.). EPO-R neutralization was performed using anti-EPOR antibodies (C-20 and M-20; Santa Cruz Biotechnology Inc.). TG101348 was synthesized by the UNC-CH Center for Integrative Chemical Biology and Drug Discovery based on its publically available structure.

Serial sphere assay. Mammospheres were passaged using $0.05 \%$ trypsin $/ 0.53$ $\mathrm{mmol} / 1 \mathrm{EDTA}-4 \mathrm{Na}$ and filtered through a $40-\mu \mathrm{M}$ cell strainer. 20,000 dissociated cells per well were replated in $2 \mathrm{ml}$ mammosphere medium as above. Sphere-forming efficiency was calculated by dividing the number of mammospheres formed by the original number of single cells seeded and is expressed as a percentage. Each experiment was performed in triplicate.

MMTV-Wnt1 sphere assays. Mouse MMTV-Wnt 1 tumors were minced with a razor blade and suspended in $10 \mathrm{ml}$ of L-15 Leibovitz medium (Thermo Scientific) supplemented with $500 \mu \mathrm{l}$ of collagenase/hyaluronidase (cat. $\# 07912$; Stem Cell Technologies). Tumors were digested for 2 hours at $37^{\circ} \mathrm{C}$ with pipetting every 30 minutes. Then, HBSS with $2 \%$ HICS was added to inactivate the collagenases. After pelleting, cells were treated serially with trypsin, dispase, DNase, and ACK lysis buffer. Cells were then stained with lineage cocktail (antibodies against CD31, CD45, and CD140a) and antibodies against CD49f and CD24 in HBSS with 2\% HICS. Viable, Lin ${ }^{-} \mathrm{CD} 24^{\mathrm{hi}} \mathrm{CD} 49 \mathrm{f}^{\text {hi }}$ cells were sorted and cultured in Matrigel with vehicle or EPO (1 IU/ml) in DMEM/F12 medium with $2 \%$ B27, $20 \mathrm{ng} / \mathrm{ml}$ murine EGR, $20 \mathrm{ng} / \mathrm{ml}$ recombinant basic FGF, and $1 \%$ penicillin/streptomycin. After 10-14 days, colonies were counted using Clono-Counter (52).

Mouse colony and orthotopic injections. FVB/NJ, C3-Tag, and MMTV-Neu mice were purchased from the Jackson Laboratory.

For the GEMMs of breast cancer studies, 6-week-old virgin C3-Tag mice were treated with i.p. injections of either saline (PBS) or Procrit (EPO; Amgen). MMTV-Neu mice began EPO treatment 4 weeks after parturition; mice were dosed i.p. $500 \mathrm{IU} / \mathrm{kg}$ biweekly (BIW). Mice were sacrificed when maximum tumor size $(1.3 \mathrm{~cm})$ was reached.

For orthotopic injection of C3-Tag-luc cells, cells were trypsinized and resuspended in HBSS with $2 \%$ FBS. $1 \times 10^{5}$ cells were resuspended in $100 \mu \mathrm{l}$ of HBSS/Matrigel (354234; BD Biosciences), mixed (1:1 volume), and injected into the lower right mammary fat pad of $\mathrm{FVB} / \mathrm{NJ}$ female mice (6-8 weeks of age). Administration of saline or EPO (500 IU $/ \mathrm{kg}$, BIW) was started 1 week after the injection. Bioluminescence imaging was done using IVIS Kinetic Optical System.

MMTV-Wnt-1 tumor cells were dissociated with gentleMACS dissociator (Miltenyi Biotec Inc.) following the manufacturer's instructions for making single-cell suspensions from implanted mouse tumors. $2 \times 10^{5}$ cells were injected into the lower right mammary fat pads of FVB/ $\mathrm{NJ}$ female mice as described for the C3-Tag-luc cells $(n=40)$. When orthotopic tumors reached $5 \mathrm{~mm}$ in length and width, mice were randomized to treatment with vehicle, carboplatin $(37.5 \mathrm{mg} / \mathrm{kg} / \mathrm{d}$, i.p.), TG101348 (240 $\mathrm{mg} / \mathrm{kg} / \mathrm{d}$, crow), or a combination of carboplatin and TG101348 (37.5 mg/ $\mathrm{kg} / \mathrm{d}$ and $240 \mathrm{mg} / \mathrm{kg} / \mathrm{d}$ i.p. respectively).

LDA assay. MMTV-Wnt1 orthotopic tumors were dissociated and the indicated number of DAPI-Lin- tumor cells were then implanted into the mammary fat pads of FVB mice. Mice were observed weekly for 2 months for tumor formation. Tumorigenic cell frequencies were calculated using L-Calc (StemCell Technologies).

Complete blood counts. Hematocrit measurements were run on a Hemavet 950 hematology system (Drew Scientific).

Microarray and GSEA. TICs $\left(\mathrm{CD} 44^{+} \mathrm{CD} 24-\mathrm{EpCAM}^{+}\right)$from SUM149 cells were sorted as described above. After sorting, 10,000 cells were resuspended in MammoCult Basal Medium and starved for 2 hours, then treated with either PBS or EPO (1 IU/ml) for 16 hours. Total RNA was extracted from 2 independent sortings. All samples were profiled as described previously using oligo microarrays (Agilent Technologies) and uploaded to NCBI Gene Expression Omnibus (GSE51433) (53). All microarray and patient clinical data are available in the UNC-CH Microarray Database (https:// genome.unc.edu/pubsup/breastGEO/clinicalData.shtml). single-sample gene set enrichment analysis (ssGSEA) (Broad Institute) was performed on log-transformed median centered data. All gene sets are part of the Molecular Signature Database v3.1 curated gene sets (http://www.broad. mit.edu/gsea/msigdb/).

For additional information, see Supplemental Methods.

Statistics. Mouse Kaplan-Meier tumor-free or overall survival was analyzed using GraphPad Prism 4.0 software (GraphPad Software Inc.), and comparisons were made using the log-rank test. Tumor sizes were compared using an unpaired, 2-tailed $t$ test. Human Kaplan-Meier relapse-free survival was analyzed in R (http://www.r-project.org/) using the library survival in the R project. All data are graphed as mean \pm SEM, unless otherwise noted. All box and whisker plots represent 25 th to 75 th percentiles, with whiskers representing the range and the line denoting the median value. $P<0.05$ was considered significant.

Study approval. All studies involving mice were performed with approval from the IACUCs at UNC-CH.

\section{Acknowledgments}

We acknowledge the members of the Kim lab for useful discussions, and UNC-CH's Mouse Phase 1 Unit, Animal Studies Core, Translational Pathology Laboratory, CGIBD, Flow Cytometry Core, and Genomics Core for their technical assistance. This work was supported by NIH R01 CA142794 (to W.Y. Kim), NIH P30 CA147933 (to M. Diehn), and U54 CA151652 (to W.Y. Kim), Integrative Vascular Biology Training grant T32-HL069768 (to J.S. Damrauer), Lineberger Comprehensive Cancer Center Postdoctoral training grant T32-CA009156 (to T. Hadzic), the DoD grants PC094631 and W81XWH-08-1-0064 (to W.Y. Kim), and California Institute for Regenerative Medicine Training grant TG2-01159 (to Y. Jeong). W.Y. Kim is a Damon Runyon Merck Clinical Investigator.

Received for publication March 12, 2013, and accepted in revised form October 24, 2013.

Address correspondence to: William Y. Kim, Lineberger Comprehensive Cancer Center, University of North Carolina, CB\# 7295, Chapel Hill, North Carolina 27599-7295, USA. Phone: 919.966.4765; Fax: 919.966.8212; E-mail: wykim@med.unc.edu.
1. Kaelin WG, Ratcliffe PJ. Oxygen sensing by metazoans: the central role of the HIF hydroxylase pathway. Mol Cell. 2008;30(4):393-402.

2. Jelkmann W, Bohlius J, Hallek M, Sytkowski AJ.
The erythropoietin receptor in normal and cancer tissues. Crit Rev Oncol Hematol. 2008;67(1):39-61.

3. Kim WY, et al. Failure to prolyl hydroxylate hypoxiainducible factor alpha phenocopies VHL inactiva- tion in vivo. EMBO J. 2006;25(19):4650-4662.

4. Gruber M, et al. Acute postnatal ablation of Hif$2 \alpha$ results in anemia. Proc Natl Acad Sci U S A. 2007; 104(7):2301-2306. 
5. Scortegagna $\mathrm{M}$, et al. HIF- $2 \alpha$ regulates murine hematopoietic development in an erythropoietindependent manner. Blood. 2005;105(8):3133-3140.

6. Jelkmann W. Developments in the therapeutic use of erythropoiesis stimulating agents. BrJ Haematol. 2008;141(3):287-297.

7. Hardee ME, Arcasoy MO, Blackwell KL, Kirkpatrick JP, Dewhirst MW. Erythropoietin biology in cancer. Clin Cancer Res. 2006;12(2):332-339.

8. Farrell F. The Erythropoietin Receptor and its expression in tumor cells and other tissues. Oncologist. 2004;9(suppl 5):18-30.

9. Parganas E, et al. Jak2 is essential for signaling through a variety of cytokine receptors. Cell. 1998; 93(3):385-395.

10. Spivak JL. The anaemia of cancer: death by a thousand cuts. Nat Rev Cancer. 2005;5(7):543-555.

11. Glaspy J, et al. Impact of therapy with epoetin alfa on clinical outcomes in patients with nonmyeloid malignancies during cancer chemotherapy in community oncology practice. Procrit Study Group. J Clin Oncol. 1997;15(3):1218-1234.

12. Henke M, et al. Erythropoietin to treat head and neck cancer patients with anaemia undergoing radiotherapy: randomised, double-blind, placebocontrolled trial. Lancet. 2003;362(9392):1255-1260.

13. Demetri GD, Kris M, Wade J, Degos L, Cella D. Quality-of-life benefit in chemotherapy patients treated with epoetin alfa is independent of disease response or tumor type: results from a prospective community oncology study. Procrit Study Group. J Clin Oncol. 1998;16(10):3412-3425.

14. Leyland-Jones B, et al. Maintaining normal hemoglobin levels with epoetin $\alpha$ in mainly nonanemic patients with metastatic breast cancer receiving first-line chemotherapy: a survival study. J Clin Oncol. 2005;23(25):5960-5972.

15. Gabrilove JL, et al. Clinical evaluation of onceweekly dosing of epoetin alfa in chemotherapy patients: improvements in hemoglobin and quality of life are similar to three-times-weekly dosing. J Clin Oncol. 2001;19(11):2875-2882.

16. Wright JR, et al. Randomized, double-blind, placebocontrolled trial of erythropoietin in non-smallcell lung cancer with disease-related anemia. J Clin Oncol. 2007;25(9):1027-1032.

17. Smith RE, et al. Darbepoetin $\alpha$ for the treatment of anemia in patients with active cancer not receiving chemotherapy or radiotherapy: results of a phase III, multicenter, randomized, double-blind, placebocontrolled study. J Clin Oncol. 2008;26(7):1040-1050.

18. Littlewood TJ, et al. Effects of epoetin $\alpha$ on hematologic parameters and quality of life in cancer patients receiving nonplatinum chemotherapy: results of a randomized, double-blind, placebo-controlled trial. JClin Oncol. 2001;19(11):2865-2874.

19. Savonije JH, et al. Effects of early intervention with epoetin $\alpha$ on transfusion requirement, hemoglobin level and survival during platinum-based chemotherapy: Results of a multicenter randomised controlled trial. Eur J Cancer. 2005;41(11):1560-1569.

20. Chang J, Couture F, Young S, McWatters K-L,
Lau CY. Weekly epoetin $\alpha$ maintains hemoglobin, improves quality of life, and reduces transfusion in breast cancer patients receiving chemotherapy. J Clin Oncol. 2005;23(12):2597-2605.

21. Vansteenkiste J, et al. Double-blind, placebo-controlled, randomized phase III trial of darbepoetin $\alpha$ in lung cancer patients receiving chemotherapy. J Natl Cancer Inst. 2002;94(16):1211-1220.

22. Hardee ME, et al. Erythropoietin inhibits apoptosis in breast cancer cells via an Akt-dependent pathway without modulating in vivo chemosensitivity. Mol Cancer Ther. 2006;5(2):356-361.

23. Arcasoy MO. Erythropoiesis-stimulating agent use in cancer: preclinical and clinical perspectives. Clin Cancer Res. 2008;14(15):4685-4690.

24. Hedley BD, et al. Recombinant human erythropoietin in combination with chemotherapy increases breast cancer metastasis in preclinical mouse models. Clin Cancer Res. 2011;17(19):6151-6162.

25 . Lee AS, et al. Erythropoietin induces lymph node lymphangiogenesis and lymph node tumor metastasis. Cancer Res. 2011;71(13):4506-4517.

26. Lai SY, et al. Erythropoietin-mediated activation of JAK-STAT signaling contributes to cellular invasion in head and neck squamous cell carcinoma. Oncogene. 2005;24(27):4442-4449.

27. Lopez TV, et al. Autocrine/paracrine erythropoietin signalling promotes JAK/STAT-dependent proliferation of human cervical cancer cells. Int J Cancer. 2011;129(11):2566-2576.

28. Okazaki T, et al. Erythropoietin promotes the growth of tumors lacking its receptor and decreases survival of tumor-bearing mice by enhancing angiogenesis. Neoplasia. 2008;10(9):932-939.

29. LaMontagne KR, et al. Recombinant epoetins do not stimulate tumor growth in erythropoietin receptorpositive breast carcinoma models. Mol Cancer Ther. 2006;5(2):347-355.

30. Sinclair AM, et al. Expression and function of erythropoietin receptors in tumors. Cancer. 2007; 110(3):477-488.

31. Hardee ME, et al. Human recombinant erythropoietin (rEpo) has no effect on tumour growth or angiogenesis. Br J Cancer. 2005;93(12):1350-1355.

32. Blackwell KL, et al. Human recombinant erythropoietin significantly improves tumor oxygenation independent of its effects on hemoglobin. Cancer Res. 2003;63(19):6162-6165.

33. Maroulakou IG, Anver M, Garrett L, Green JE. Prostate and mammary adenocarcinoma in transgenic mice carrying a rat C3(1) simian virus 40 large tumor antigen fusion gene. Proc Natl Acad Sci U S A. 1994; 91(23):11236-11240.

34. Guy CT, et al. Expression of the neu protooncogene in the mammary epithelium of transgenic mice induces metastatic disease. Proc Natl Acad Sci U S A. 1992;89(22):10578-10582.

35. Fillmore CM, Kuperwasser C. Human breast cancer cell lines contain stem-like cells that self-renew, give rise to phenotypically diverse progeny and survive chemotherapy. Breast Cancer Res. 2008;10(2):R25.

36. Cho RW, et al. Isolation and molecular characteriza- tion of cancer stem cells in MMTV-Wnt-1 murine breast tumors. Stem Cells. 2008;26(2):364-371.

37. Marotta LLC, et al. The JAK2/STAT3 signaling pathway is required for growth of $\mathrm{CD} 44^{+} \mathrm{CD} 24^{-}$ stem cell-like breast cancer cells in human tumors. J Clin Invest. 2011;121(7):2723-2735.

38. Li Z, et al. Hypoxia-inducible factors regulate tumorigenic capacity of glioma stem cells. Cancer Cell. 2009;15(6):501-513.

39. Wernig G, et al. Efficacy of TG101348, a selective JAK2 inhibitor, in treatment of a murine model of JAK2V617F-induced polycythemia vera. Cancer Cell. 2008;13(4):311-320.

40. Prat A, et al. Phenotypic and molecular characterization of the claudin-low intrinsic subtype of breast cancer. Breast Cancer Res. 2010;12(5):R68.

41. Harrell JC, et al. Genomic analysis identifies unique signatures predictive of brain, lung, and liver relapse. Breast Cancer Res Treat. 2012;132(2):523-535.

42. Masuda S, et al. A novel site of erythropoietin production. Oxygen-dependent production in cultured rat astrocytes. J Biol Chem. 1994;269(30):19488-19493.

43. Yasuda Y, et al. Estrogen-dependent production of erythropoietin in uterus and its implication in uterine angiogenesis. J Biol Chem. 1998;273(39):25381-25387.

44. Wang GL, Semenza GL. Characterization of hypoxia-inducible factor 1 and regulation of DNA binding activity by hypoxia. J Biol Chem. 1993; 268(29):21513-21518.

45. Bhati R, et al. Molecular characterization of human breast tumor vascular cells. Am J Pathol. 2008; 172(5):1381-1390.

46. Phillips TM, Kim K, Vlashi E, McBride WH, Pajonk F. Effects of recombinant erythropoietin on breast cancer-initiating cells. Neoplasia. 2007;9(12):1122-1129.

47. Liang K, et al. Recombinant human erythropoietin antagonizes trastuzumab treatment of breast cancer cells via Jak2-mediated Src activation and PTEN inactivation. Cancer Cell. 2010;18(5):423-435.

48. Gabrilove JL, Perez EA, Tomita DK, Rossi G, Cleeland CS. Assessing symptom burden using the M. D. Anderson symptom inventory in patients with chemotherapy-induced anemia: results of a multicenter, open-label study (SURPASS) of patients treated with darbepoetin-alpha at a dose of 200 microg every 2 weeks. Cancer. 2007;110(7):1629-1640.

49. Xue Y, et al. PDGF-BB modulates hematopoiesis and tumor angiogenesis by inducing erythropoietin production in stromal cells. Nat Med. 2011;18(1):100-110.

50. Troester MA, et al. Cell-type-specific responses to chemotherapeutics in breast cancer. Cancer Res. 2004;64(12):4218-4226.

51. Livak KJ, Schmittgen TD. Analysis of relative gene expression data using real-time quantitative PCR and the 2(-Delta Delta $\mathrm{C}(\mathrm{T}))$ Method. Methods. 2001;25(4):402-408.

52. Niyazi M, Niyazi I, Belka C. Counting colonies of clonogenic assays by using densitometric software. Radiat Oncol. 2007;2(1):4.

53. Kim WY, et al. HIF $2 \alpha$ cooperates with RAS to promote lung tumorigenesis in mice. J Clin Invest. 2009;119(8):2160-2170. 